\section{Volcanoes and eruptions}

Volcanoes of the Earth. (Revised edition.) By Fred M. Bullard. Pp. 579. (University of Texas Press : Austin and London, 1976.) £20.

Volcanoes of the Earth is, as the dust jacket blurb states, a revised and enlarged edition of Bullard's Volcanoes: In History, In Theory, In Eruption, first published in 1962. It is a handsome volume, very satisfying to leaf through and to have on one's shelves. In contrast to the numerous cheaply produced textbooks that one encounters these days, this one gives the impression of being a real book, and one which the publishers seem to have spared no expense in producing. There are, of course, numerous text figures and photographs, most of them excellent, and even a section of colour photographs. Most striking, however, is the liberal use of white paper. Many diagrams have a whole page to themselves, and the text pages have six centimetre margins.

There are three main parts to the text. The first deals with the background to volcanology, the second covers the types of eruptions, and the third is rather a hotch-potch entitled "Theory, Cycles, Utilization and Environmental Effects of Volcanoes".

The core of the book is the section on types of volcanic eruptions, and it is here that its major strengths and weaknesses lie. Almost all of the useful parts of the book are concentrated in this section; detailed histories of individual volcanoes and eruptions. Bullard exhibits the evidence of much patient scholarship here. He has obviously tracked down and read a vast number of original references, including some very obscure ones. To take just one example, his account of the eruption of $\mathrm{Mt}$ Katmai in 1912 and the subsequent scientific investigations is unquestionably better than any other book in print. Many other authors have written about the same events, but they have based their accounts on secondary or even tertiary sources, thus blurring and muddying the facts. Having gone right back to the primary sources, Bullard's descriptions have a notable freshness and precision. Neither are they mere dry reviews. Bullard uses his narrative skill to present his material in a thoroughly readable, stimulating stylc.

Having said this, it is unfortunate that one has to look at the other, tarnished side of the coin. Bullard nowhere discusses adequately the criteria by which he recognises different types of eruption, and often seems to confuse a type of eruption with an individual volcano. Thus, chapter 9 on "The Strombolian Type of Volcanic Eruption" makes no mention of any volcano other than Stromboli. (About one-third of the chapter describes a visit made by Bullard and his wife to the island.) Similarly, chapter 10 on "The Hawaiian Type of Volcanic Eruption" deals exclusively with eruptions in the Hawaiian islands. In chapter 9, Bullard does at least begin with a few vague comments on the nature of Strombolian eruptions; in chapter 10 , he prefers to discuss Captain Cook and the early history of the islands.

The book would have been strengthened by at least some discussion of modern work on classification of volcanic eruptions by granulometric analysis of pyroclastic material. This omission is characteristic of the text as a whole. The dust jacket proclaims that "Recent advances in heat flow studies and the concept of sea floor spreading and plate tectonics are incorporated to present a view of volcanology consistent with our present state of knowledge". This is emphatically not the

\section{Crystalline rocks}

Evolution of the Crystalline Rocks. Edited by D. K. Bailey and R. Macdonald. Pp. ix +484. (Academic: London and New York, 1976.) £16; \$35.

Armost half a century has elapsed since the appearance of Bowen's Evolution of the Igneous Rocks (1928). In that time major advances in both cquipment and exp rimental techniques have led to a wealth of published experimental data, presenting the contributors with an unenviable task in writing a sequel to Bowen's work, within the confines of a single volume. Not surprisingly all aspects of the contribution of experimental petrology to the understanding of the evolution of crystalline rocks could not be covered, but the omissions in the igneous section, noticeably the basic and intermediate rocks, have led to a marked imbalance in the text.

The opening chapter on experimental methods offers a basic introduction for newcomers to experimental petrology. More detailed accounts of specific techniques can be found in the references cited. The choice of PT subdivisions in the metamorphic section has inevitably led to a certain amount of duplication. This has, however, resulted in some interesting insights into the differing criteria used by individual contributors in assessing the various conflicting sets of data (see Greenwood and Schreyer on the stability of $\mathrm{Al}_{2} \mathrm{SiO}$; polymorphs).

Newton and Fyfe give a comprehen- case. In fact, the book has generally a somewhat dated atmosphere to it. Only a small proportion of the many works referenced were published in this decade. There are, indeed, two chapters on island arcs and plate tectonics, but they sit rather uncomfortably at the end of the book as rather unnecessary appendages, not well integrated with the rest of the text. They are competent enough reviews, but are unlikely to be of much value at present, when there are so many other good reviews around, and particularly because Bullard dampens any enthusiasm his readers may have for plate tectonics by implying quite clearly that he is not terribly impressed by it all.

In summary, Volcanoes of the Earth is an excellent source of facts on historical volcanic eruptions. As a review of modern volcanology it leaves much to be desired.

Peter Francis

Peter Francis is Lecturer in Earth Sciences at The Open University, Milton Keynes, UK.

sive account of blueschist metamorphism (57 pages), but have rather scantily covered eclogites and granulites (10 pages). Greenwood offers one of the best sections, striking a very good balance between the major aspects of experimental petrology and its application to quantifying the intensive parameters in a range of metamorphic rocks. Schreyer has adopted a slightly different approach concentrating more on the phase chemistry aspects at high temperatures and low pressures.

The section on granitic rocks is mainly concerned with the crystallisation of haplo granitic melts. The reader's attention is drawn to the paucity of data for water undersaturated systems and the composition of the vapour phase in equilibrium with solidus reactions. In his concluding remarks, Luth has essentially critically reviewed his own contribution, by pointing out the omissions in dealing with the ultimate source of granitic melts and the volcanic rocks of granitic composition. Bailey presents a very concise review of the major aspects of alkaline rocks, delineating some of the problems in the genesis and subsequent crystallisation of the melts.

The imbalance in some of the contributions and the questionable policy of omitting certain major aspects of igneous experimental petrology will probably reduce the usefullness of this book as an undergraduate text.

J. Nolan

J. Nolan is Lecturer in Petrology in the Geology Department, Imperial College, London, UK. 